\title{
TINDAK TUTUR TERIMA KASIH: PERBANDINGAN METABAHASA MAKNA DALAM KORPUS WEB INDONESIA DAN MALAYSIA
}

\author{
Levinda Hesty Suryawardhani \\ suryalevinda@gmail.com \\ Universitas Negeri Malang
}

\begin{abstract}
Social harmony is a basic element of the realization of social life in a neighborhood. One of the way to establish it is by the speech that is appropriately used in giving gratitude. As neighboring countries, Indonesia and Malaysia have the same language background despite having different cultures. This can be demonstrated through the differences in the use speech acts that are used by speakers of both countries in giving gratitude. Implementing corpus methodology, this study aims to investigate the speech acts in Indonesian and Malaysian languages by analyzing concordance data for words used in giving gratitude in both language. The findings indicateed that there were similarities as well as difference in the speech acts used in giving gratitudes. The similarities of the linguistic background is asociated with the similar used of the terms in giving gratitude. Meanwhile, the differences in the speech acts that were found can be linked to the governance culture of both countrie.
\end{abstract}

Keywords: corpus concordance, natural semantic metalanguage, speech acts, gratitude

\begin{abstract}
Abstrak
Harmoni sosial meupakan elemen dasar terwujudnya kehidupan sosial bertetangga yang dapat diwujudkan salah satunya melalui tindak tutur terimakasih yang digunakan secara tepat. Sebagai negara yang bertetangga, Indonesia dan Malaysia mempunyai kesamaan latar bahasa meski memiliki budaya yang berbeda. Hal ini dapat ditunjukkan melalui perbedaan penggunaan tindak tutur terimakasih oleh penutur kedua negara tersebut. Penelitian ini bertujuan untuk menginvestigasi tindak tutur terima kasih dalam bahasa Indonesia dan Malaysia dengan memanfaatkan korpus dalam menganalisis data konkordansi kata terima kasih di kedua bahasa. Penemuannya mengindikasikan bahwa tindak tutur terimakasih digunakan secara sama dan sekaligus berbeda. Faktor kesamaan latar bahasa dan budaya pemerintahan kedua negara dapat diasosiasikan dengan hasil temuan.
\end{abstract}

Kata kunci: konkordansi korpus, metabahasa makna alami, tindak tutur terima kasih

\section{PENDAHULUAN}

Harmoni sosial merupakan elemen dasar terwujudnya kehidupan sosial bersama, bekerjasama, dan bertetangga. Indonesia dan Malaysia adalah negara tetangga yang diidentifikasi memiliki kesamaan latar bahasa yang sama-sama berasal dari bahasa Melayu (Kwary \& Jalaludin, 2015). Akan tetapi, seiring berjalannya waktu, kedua negara yang memiliki akar bahasa yang sama tersebut menumbuhkan dua bahasa moderen yang sekarang dikenal sebagai bahasa Indonesia dan bahasa Melayu. 
Namun, meski Indonesia dan Malaysia terlihat memiliki banyak kesamaan yang dapat dilihat dari tumpang tindih bahasa dan sejarah nusantara (Kremer, 2011), tercatat pula beberapa perbedaan diantara keduanya sebagai akibat dari intepretasi sejarah yang melahirkan budaya yang sedikit berbeda (Holst, 2007). Meskipun demikian, perbedaan budaya tidak seharusnya merusak harmoni sosial yang telah tercipta.

Beberapa penelitian mencatat, bahwa menjaga harmoni sosial dapat dilakukan salah satunya dengan mengaplikasikan kemampuan mengungkapkan terima kasih secara tepat (Gordon, 1999; Allen, 2001). Menurut Jacobson (2002) tindak berterimakasih merupakan sebuah fenomena kesopanan dalam bahasa dan budaya Inggris modern. Lebih lanjut, dijelaskan oleh Allen (2001) dalam penelitiannya tentang ungkapan terimakasih di Jepang, bahwa ungkapan terima kasih adalah salah satu dari sekian banyak strategi kesopanan yang dapat digunakan untuk memupuk solidritas sosial. Kemudian menurut Leech (1983) ungkapan terimakasih sebagai wujud harmoni sosial yang dapat mengurangi kesenjangan sosial. Sedangkan menurut Searly (1979) dalam Yule (1996), ungkapan terimakasih termasuk dalam tindak ilokusi yang menujukkan rasa syukur.

Dari beberapa penelitian tentang tindak tutur terima kasih diatas, dapat dilihat bahwa tindak tutur, tidak semata-mata murni dikaji dengan kajian bahasa, tetapi juga menyertakan kajian sosial budaya masyarakat penuturnya.

Studi mengenai tindak tutur terima kasih yang mengikutsertakan analisis sosial budaya sudah mulai banyak dilakukan, diantaranya adalah studi tindak tutur terimakasih yang dilakukan oleh Saifudin (2010) yang mengidentifikasi faktor sosial budaya dan kesopanan dalam tindak tutur terima kasih di bahasa Jepang. Hasilnya menunjukkan bahwa adanya variasi dalam tindak tutur terimakasih dipengaruhi oleh faktor sosial budaya, yakni hubungan sosial antar penuturnya. Penelitian lain dilakukan oleh Naoto \& Washizu (2015) yang mereview variasi dan universalitas budaya yang mempengaruhi tindak tutur terimakasih di kawasan Asia Timur. Di bagian akhir studi disarankan agar penelitian selanjutnya memaparkan perbedaan budaya dalam menginvestigasi tindak tutur terimakasih. Masih seputar penelitian tindak tutur terimakasih, Pisghadam \& Zarei (2012) membandingkan penggunaan tindak tutur pada pelajar bahasa Inggris dari Persia, China dan juga penutur asli bahasa Inggris, untuk mengetahui pola ungkpan terimakasih diantara penutur-penutur yang berasal dari budaya yang berbeda tersebut. Pada penelitian ini, para pelajar yang menjadi partisipan diminta untuk melengkapi kuesioner dalam bentuk Discourse Completion Test (DCT). Penemuan dari studi ini mengungkap bahwa meski ungkapan terimakasih menjadi strategi favorit diantara semua kelompok pasrtisipan, tetap ditemukan adanya perbedaan cara menggunakan ungkapan tindak tutur terimakasih di ketiga kelompk patisipan dari latar budaya yang berbeda. Mayar, Farnia, \& Sattar (2015) menambahkan studi yang membandingkan ekspresi terimakasih anatara pelajar Malaysia dan Pelajar Irania yang sama-sama belajar di Malaysia dengan menngunakan kuesioner dan interview. Hasil studinya 
mengindikasikan bahwa terimakasih merupakan strategi yang paling sering digunakan dan menekankan pentingnya pemahaman fungsi komunikatif dan pengetahuan aspek kultural bahasa.

Dari keempat penelitian tentang tindak tutur terimaksih diatas, keempatnya telah mengakomodasi kajian sosial budaya di dalamnya. Namun, dua penelitian awal masih terbatas pada satu budaya saja, sedangkan dua penelitian berikutnya sudah melakukan studi perbandingan tindak tutur terimaksih di dua bahkan lebih budaya. Meskipun demikian, dari keempatnya belum teridentifikasi adanya penelitian tentang tindak tutur terimakasih pada bahasa dan budaya yang berbeda yang memanfaatkan sarana penunjang berupa korpus. Maka dari itu, penelitian ini bertujuan untuk menivestigasi pola tindak tutur terimakasih pada bahasa dan budaya Indonesia dan Malaysia dengan bantuan korpus.

\section{LANDASAN TEORI}

\section{Speech Act}

Austin (1975) dalam Wardhaugh \& Fuller (2015) membagi itndak tutur menjadi tiga yaitu lokusi, ilokusi, dan perlokusi. Tindak tutur lokusi adalah tindak tutur yang digunakan untuk menyatakan sesuatu. Ilokusi adalah maksud dari penutur misalnya penyampaian informasi, perintah, dan peringatan. Sedangkan, jika tuturan yang diucapkan penutur memberi dampak atau pengaruh terhadap perilaku mitra tuturnya, maka tindak tutur tersebut disebut dengan perlokusi. Dalam Yule (1996), Searle (1979) mengkasifikasi tindak tutur ilokusi dalam beberapa jenis yaitu, deklaratif ( declarations ), representatif (representatives), ekspresif ( expressives ), direktif ( directives ), dan komisif (commisives ). Secara lebih rinci, berikut penjelasan mengenai macam-macam tindak tutur ilokusi:

1. Deklaratif, yaitu tindak tutur yang dimaksudkan penuturnya untuk menciptakan hal (stastus, keadaan dsb) yang baru. Tindak tutur deklaratif adalah jenis tindak tutur yang mengubah dunia melalui ucapan penutur dan mitra tutur, seperti memaafkan, menghukum, membatalkan, pemecatan dan pembaptisan. Misalnya pengucapan ijab qobul oleh calon mempelai pria yang menyebabkan statusnya berganti menjadi suami dan calon mempelai perempuan statusnya berganti menjadi seorang istri.

2. Representatif yaitu tuturan yang mengikat penuturnya akan kebenaran atas apa yang diujarkan. Tindak tutur jenis ini berupa pernyataan, ramalan, mengeluh, membanggakan, mengakui, memberi kesaksian dan menyarankan.

3. Ekspresif yaitu tindak tutur yang dimaksudkan penuturnya agar ujarannya diartikan sebagai evaluasi tentang hal yang disebutkan dalam tuturan itu seperti ucapan terima kasih, meminta maaf, dan ucapan selamat. Biasanya, kalimat ekspresif lebih mengacu pada hal yang sedang dirasakan oleh si penutur itu. 
4. Direktif yaitu tindak tutur yang dimaksudkan penuturnya agar si pendengar melakukan tindakan yang disebutkan dalam tindakan itu seperti perintah, larangan, peringatan, mengusulkan, memohon, atau mendesak. Kalimat ini lebih mengacu pada keinginan penutur terhadap suatu hal atau situasi tertentu.

5. Komisif yaitu tindak tutur yang mengikat penuturnya untuk melaksanakan apa yang disebutkan di dalam tuturannya seperti berjanji, ancaman, tawaran, menyetujui, atau bersumpah. Tindak tutur ini menitikberatkan pada komitmen penutur terhadap tindakannya di masa yang akan datang.

\section{Natural Semantic Metalanguage}

Wierbizcka(2003) mencatat dalam bukunya, bahwa variasi bahasa dari berbagai norma dan tradisi kultural yang berbeda dapat dianalisa dengan berdasar pada semantik primitive universal atauyang mendekati-universal yang dikenal sebagainaturalsemantic metalanguage. Metabahasa semantik natural ini dapat mengakomodasi berbagai tindak tutur, peristiwa tutur, dan situasi tutur yang berbeda-beda di setiap bahasa dan budaya melalui perspektif yang lebih independen. Maher (2002) menambahkan bahwa teori metabahasa semantik natural menawarkan metodologi untuk menganalisis bahasa dari budaya tertentu secara lebih jelas dan tidak etnosentris dengan menggunakan sekitar 60 konsep mini leksikon, yang disebut-sebut universal yakni dapat dileksikalisasikan di semua bahasa. Dari keenampuluh leksikon tersebut dapat dikategorikan dalam domain semantik berikut ini: substantives, determiners, quantifiers, attributes, mental predicates, speech, actions, events dan movements, existence dan possession, life dan death, logical concepts, time, space, intensifier atau augmentor, taxonomy atau partonomy, similarity. Metabahasa semantik natural ini menerangkan setiap interaksi melalui konsep-konsep dan komponen semantik universal seperti 'I want something', 'I know something', 'you know something', 'I don't want this', 'I/you/someone did something bad', 'I don't want this', 'I want you to say something', 'I want you to do something', dan sebagainya.

\section{METODE PENELITIAN}

Penelitian ini menggunakan pendekatan deskriptif kualitatif. Analisis kualitatif pada korpus mengadopsi metode penjabaran dan pemaparan terperinci untuk mengobservasi fenomena linguistik yang tersimpan secara digital sebagai korpus yang dapat diakses melalui perangkat komputer (Hasko, 2012). Data penelitin ini didapat dari dua korpus yang diambil dari Sketch Engine, i.e. Indonesian Web (Indonesian WaC) dan Malaysian Web (Malyasian WaC). Data diperoleh memalui serangkaian proses, pertama-tama masuk ke akun web Sketch Engine di https://the.sketchengine. co.uk. Setelah itu, cari korpus IndonesianWac, lalu memasukkkan kata "terima kasih" pada kolom yang tersedia dan klik konkordansi. Kemudian, data yang akan digunakan yang berupa konkordansi dapat diamati untuk kemudian dianalisis. Begitu pula untuk 
mencari konkordansi dalam korpus Malaysia, mengikuti langkah-angkah yang serupa.

Setelah data diperoleh, kemudian masing-masing konkordansi kata terima kasih dari korpus bahasa Indonesia dan Malaysia diobservasi menggunakan teori speech act (Austin, 1975 dalam Wardaugh, 2015; Searle, 1979 dalam Yule, 1996) dan natural semantic metalanguage (Weirbizcka, 2003).

\section{HASIL DAN PEMBAHASAN}

Seperti yang telah dijelaskan sebelumnya, bahwa penelitian ini memanfaatkan korpus sebagai sumber data dalam menganalisis tindak tutur bersyukur melalui ungkapan terima kasih yang terdapat pada korpus IndonesianWaC dan MalaysianWaC. Dengan mengikuti langkah-langkah yang telah dijabarkan dalam metode penelitian, diperoleh data berupa konkordansi kata terima kasih di kedua korpus tersebut.

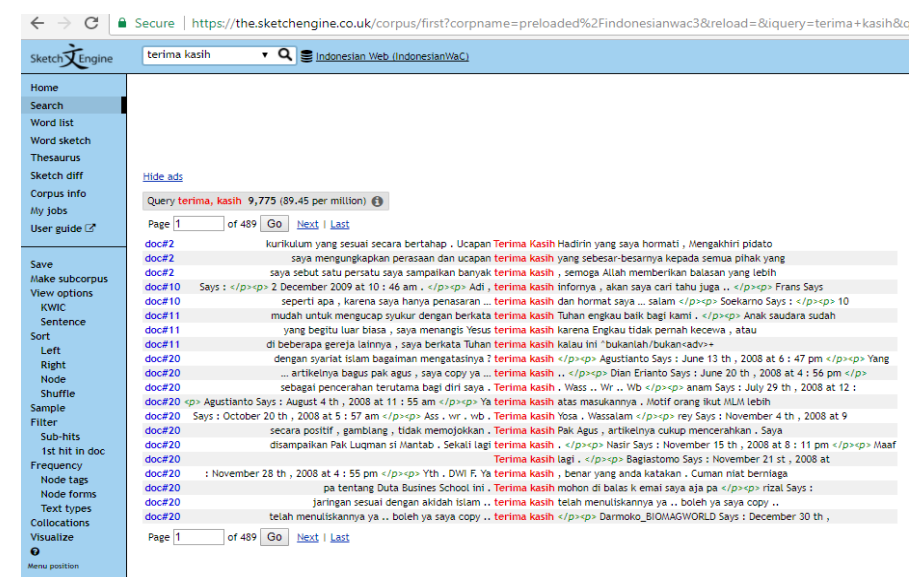

Gambar 1. Konkordansi Ungkapan Terima Kasih pada Korpus Bahasa Indonesia

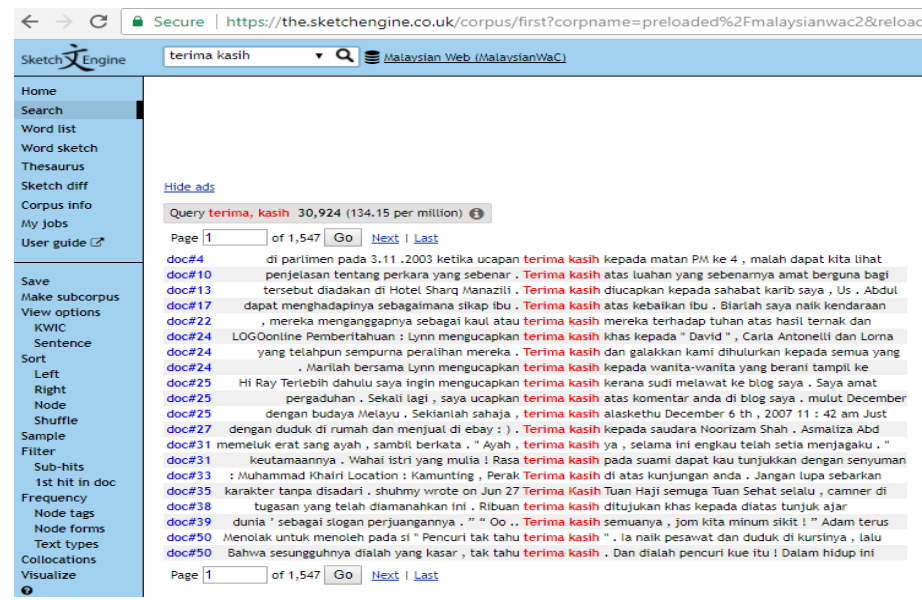

Gambar 2. Konkordansi Ungkapan Terima Kasih pada Korpus Bahasa Malaysia

Pada Gambar 1 dan Gambar 2, ditampilkan 20 kata teratas untuk konkordansi kata terimakasih pada kedua korpus bahasa Indonesia dan Malaysia. Namun penelitian ini mengambil 10 kata pertama dari konkordansi tersebut karena fokus dari penelitian 
ini adalah untuk mencari tindak tutur terimakasih seperti apa yang paling dominan di kedua negara tersebut, jadi 10 konkordansi pertama merupakan gambaran kultur spesifik dari kedua negara tersebut. Dalam pengambilan 10 konkordansi pertama ini, telah dilakukan proses sunting, jadi konkordansi yang akan ditampilkan dalam penjelasan selanjutnya merupakan konkordansi yang sudah sesuai dengan kriteria data yang dibutuhkan dalam penelitian ini.

Analisis pertama dimulai dengan menampilkan 10 konkordansi data korpus dari tindak tutur terima kasih pada bahasa Indonesia yang akan mewakili budaya bertindak tutur syukur di negara tersebut. Berikut ditampilkan Kutipan 1.

Kutipan 1

(1) Terima kasih hadirin yang saya hormati, mengakhiri pengukuhan saya...

(2) Saya mengungkapkan perasaan dan ucapan terima kasih yang sebesar-besarnya pada semua pihak yang memberi jasanya...

(3) Kepada semua yang saya sebut dan yang tidak sempat saya sebut satu-persatu. Saya sampaikan banyak terima kasih, semoga Allah memberi balasan...

(4) Terima kasih infonya, akan saya cari thau juga.

(5) Karena saya hanya penasaran, terimakasih dan hormat saya.

(6) Saya menangis Yesus terima kasih karena Engkau tidak pernah kecewa.

(7) Tuhan terima kasih kalau ini bukan karena kekuatan saya, tapi semua hanya anugerah Tuhan.

(8) Artikelnya bagus Pak, saya kopi ya. Terima kasih.

(9) Semoga bisa sebagai pencerahan terutama bagi diri saya. terima kasih.Wass..

(10) Ya, terima kash atas masukannya.

Dengan mengidentifikasi konkordansi tindak tutur terima kasih di korpus bahasa Indonesia, dapat terlihat bahwa di budaya Indonesia, penggunaan ucapan terima kasih dapat dirumuskan dengan menggunakan teori natural semantic metalanguage (Wierbizcka, 2003) ke dalam rumusan berikut ini:

\section{terima kasih}

a. I say good thing because I want to stop this now.

b. I say good thing because you do something big for me.

c. I feel and say good thing because something is good

d. I feel and say good thing because something good from something good.

e. I say good thing because I want something good from you.

f. I say good thing because I want to say that.

Penjabaran konsep tindak tutur terima kasih yang dijabarkan dengan konsep sederhana ini, membuat bagaimana tindak tutur terima kasih dipraktikkan dalam bahasa dan budaya Indonesia menjadi lebih jelas. Dari 10 pertama tindak tutur terimakasih yang ditemukan dapat dilihat bahwa pada dewasa ini, tindak tutur terima kasih digunakan dengan demikian dalam masyarakat berbahasa dan berbudaya Indonesia. Dari data konkordansinya, tindak tutur terima kasih lebih banyak digunakan untuk menyatakan 
maksud meangkhiri sesuatu, meminta sesuatu.dan menyatakan kesenangan karena diberi sesuatu. Hal tersebut dapat diamati dari Kutipan 1 poin 1 dan 5 yang merujuk pada satu konsep metabahasa makna alami yang sama, yaitu poin a, dan Kutipan 1 poin 2 dan 3 yang sama-sama mengusung konsep poin $b$, dan yang terakhir adalah poin e yang digunakan dua kali juga pada Kutipan 1 poin 8 dan 9. Seacara berurutan untuk poin c, d, dan f merujuk pada Kutipan 1 poin 4, 6, dan 10.

Dalam analisis berikutnya, ditampilkan 10 konkordansi pertama tindak tutur terima kasih yang diperoleh dari korpus bahasa Melayu untuk kemudian dijelaskan dengan menggunakan konsep metabahasa makna alami, seperti dalam Kutipan 2 berikut ini.

Kutipan 2

(1) Terima kasih atas luahan yang sebenar amat berguna bagi cikgu.

(2) Terima kasih diucapkan kepada sahabat karib saya, ust. Abdul Aziz bin Abas kerana sudi mengganti saya untuk berucap mewakili pelajar.

(3) Terima kasih atas kebaikan ibu. Biarlah saya naik kendaraan umum saja.

(4) Terima kasih khas kepada Dana....

(5) Saya ingin mengucap terima kasih kerana sudi melawat ke blog saya.

(6) Bukan berniat menimbulkan kegaduhan, sekali lagi saya ucapkan terim kasih atas komentar di blog sya.

(7) Sekianlah sahaja, terima kasih.

(8) Terima kasih kepada Noorizam Shah.

(9) Ayah, terima kasih ya selama ini engkau telah bersedia menjagaku.

(10) Terima kasih tuan haji, semiga tuan sehat selalu.

Dari konkordansi tindak tutur terima kasih diatas, dapat dianalisis dengan menggunakan teori metabahasa makna alami yang telah dibuat oleh Wirzbicka (2003) sehingga diperoleh rumusan konsep yang lebih sederhana seperti pada pemaparan berikut ini.

\section{terima kasih}

a. I say good thing because of something good.

b. I say good thing because someone do something good for me.

c. I say good thing because I want to say that.

d. I say good thing because I want to stop this now.

e. I say good thing because I feel something good about you.

Pada konkordansi tindak tutur terima kasih yang ditemukan dalam korpus bahasa Melayu, dapat disederhanakan dengan menggunakan metabahasa makna alami untuk dapat dimengerti makna universal terima kasih yang digunakan dalam bahasa dan budaya Melayu. Dari 10 konkordansi pertama yang ditemukan, menunjukkan bahwa tindak tutur terima kasih ternyata digunakan pada konteks-konteks dan tindakan tuturan yang mengimplikasikan lima hal seperti yang sudah diwakilkan dalam rumus metabahasa makna alaminya. Data yang diperoleh menujukkan bahwa tindak tutur 
terima kasih yang digunakan dalam bahasa dan budaya melayu lebih sering digunakan ketika disebabkan oleh sesuatu, seperti pada Kutipan 2 point 1,5, dan 6 yang merujuk pada poin a. Selain itu tindak tutur terima kasih juga sering digunakan ketika diberikan sesuatu, contohnya bisa dilihat di kutipan 2 poin 2, 3, dan 9 yang diekspresikan dalam metabahasa makna poin b. Selain itu, juga pada saat tidak ada sesuatu, atau hanya ingin mengungkapkannya saja, seperti pada poin c contoh kutipan 2 poin 4 dan 8 yang dapat dilihat pada poin c. Sebagai tambahan. tindak tutur terima kasih juga dapat digunakan pada situasi-situasi yang diilustrasikan dengan konsep metabahasa makna pada poin d yang merupakan konsep dari konkordansi pada kutipan 2 poin 7, dan poin e yang mewakili tindak tutur

Pada dasarnya, dari kedua analisis tentang tindak tindak tutur terima kasih yang digunakan dalam budaya orang Indonesia dan orang Melayu yang dilihat dari data konkordansinya, hampir semua komponen metabahasa makna alaminya diidentifikasi mempunyai kesamaan. Akan tetapi tetap ditemukan perbedaan diantara keduanya, meskipun tidak dalam jumlah yang terlalu signifikan.

Diketahui ada enam bentuk metabahasa makna alami yang dapat diekstrasi dari 10 konkordansi pertama tindak tutur terima kasih dalam korpus bahasa Indonesia. Sedangkan untuk konkordansi tindak tutur terima kasih pada korpus bahasa melayu dapat disederhakan ke dalam lima rumus metabahasa makna alami. Wirbizcka (2003) menyatakan bahwa penggunaan konsep metabahasa memfasilitasi peneliti untuk menemukan ungkapan makna bahasa dan budaya tertentu ke dalam istilah-istilah universal yang dapat dipahami di semua bahasa dan budaya.

Dari kedua bahasa yang hampir serupa, yang berakar rumput pada bahasa Melayu, mengakibatkan adanya tumpang tindih antara kedua bahasa ini dalam perilaku tindak tuturnya (Kremer, 2011), namun dipengaruhi orientasi politik yang berbeda mengakibatkan perkembangan kultur yang berbeda antara Indonesia dan Malaysia yang menyebabkan adanya sedikit perbedaan pada tindak tutur di kedua bahasa (Holst, 2007). Persamaan tindak tutur terlihat dari adanya kesamaan yang dapat dilihat dari konsep metabahasa makna alami untuk tindak tutur terimakasih pada konsep berikut:

I say good thing because I want to stop this now

I say good thing because I want to say that.

Di kedua bahasa, kedua konsep ini muncul. Hal ini menandakan bahwa Indonesia dan Malaysia sama-sama memiliki tradisi menggunakan tindak tutur terimakasih untuk mengakhiri atau menutup sesuatu yang bisa berupa pidato, atau sambutan. Selain itu, juga sudah menjadi budaya di kedua negara tersebut untuk mengucapkan terima kasih sebagai sebuah tindak tutur yang menunjukkan bahwa untuk mengucaokan terimakasih tidak perlu karena didasri oleh tendensi tertentu, cukup menjadi sebuah keinginan penuturnyasaja. Akan tetapi, di kedua negara yang saling bertetangga, tindak tutur terimaksih juga dapat digunakan secara berbeda. Di Indonesia tindak tutur terimakasih digunakan secara berbeda dengan di Malaysia dalam beberapa tindak tuturan yang 
dijelaskan dengan metabahasa makna berikut ini:

I say good thing because you do something big for me.

I feel and say good thing because something is good

I feel and say good thing because something good from something good.

I say good thing because I want something good from you.

Dari pemaparan metabahasa makna tindak tutur terimakasih yang ditemukan spesifik dalam bahasa Indonesia. Dalam tradisi bahasa Indonesia tindak tutur terima kasih digunakan karena terjadi sesuatu yang baik, diberi sesuatu yang besar, mendapat sesuatu dari sesuatu yang baik (Tuhan), dan untuk meminta sesuatu. Sedangkan dalam metabahasa makna alami untuk tindak tutur terimakasih di bahasa Melayu adalah sebagai berikut:

I say good thing because of something good.

I say good thing because someone do something good for me.

I say good thing because I feel something good about you.

Dalam metabahasa makna tuturan terimakasih di bahasa Melayu, terlihat bahwa tindak tutur terimaksih digunakan secara spesifik karena sesuatu yang bagus, karena diberi sesuatu yang bagus, dan karena merasa sesuatu yang baik terhadap seseorang. Jika dibandingkan keduanya berbeda dalam hal di Indonesia tindak tutur terimaksih digunakan ketika diberi sesuatu yang besar, tetapi di Malaysia ketika diberi sesuatu yang tidak harus besar yang penting baik, dan di Indonesia menggunakan terimaksih untuk meminta serta mengucapkan rasa syukur terhadap Tuhan yang secara spesifik hanya ditemukan dari data konkordansi ada di Indonesia . Hal tersebut mungkin dapat diasosiasikan dengan peratutan konstitusi kedua Negara yang berbeda, yang mana di Indonesia ketuhanan yang Maha Esa, sedangkan di Malaysia agama federasi adalah agama Islam sehingga dalam bersyukur akan lebih menggunakan kata-kata serapan bahasa yang digunakan dalam kitab keagamaan Islam dibanding kata terima kasih.

\section{KESIMPULAN}

Meskipun secara latar belakang bahasa dan sejarah memiliki kesamaan, Indonesia dan Malaysia memiliki perbedaan budaya yang diakibatkan oleh perbedaan orientasi politik yang dianut di kedua negara tersebut. Hal ini direfleksikan pada korpus di kedua bahasa. Data korpus dalam bentuk konkordansi dari kedua bahasa yang telah diamati dan dianalisis menghasilkan penemuan bahwa tindak tutur terima kasih bias digunakan secara sama dan berbeda di kedua bahasa. Hal tersebut kemudian menjadi tradisi di kedua negara. Meski demikian, perbedaan tradisi dan budaya kedua negara tersebut dapat dijelaskan secara universal dengan menggunakan konsep-konsep metabahasa makna alami. 


\section{PUSTAKA ACUAN}

Allen, S. (2001). The Management of the Communication of the Japanese Speech Act of Gratitude. Asaa e- journal of Asian Linguistics and Language Teaching.

Farnia, M., \& Sattar, H. Q. A. (2015). A Cross-Cultural Study of Iranians' and Malays' Expressions of Gratitude. Journal of Intercultural Communication, (37), N_AN_A.

Gordon, Bill.1999. Analysis of Gratitude Speech Act.

Hasko, V. (2012). Qualitative corpus analysis. In Carol A. Chapelle (Ed.) The Encyclopedia of Applied Linguistics (4758-4765). UK: Blackwell Publishing Ltd.

Holst, F. (2007). Connected History: The Indonesia-Malaysia Relationship. In E. Streifenender and A. Missbach (Eds.), Indonesia - the Presence of the Past. Berlin, German: Die Deutsche Bibliothek.

Jacobsson, M. (2002). Thank you and thanks in Early Modern English. Icame Journal, 26(2002), 63-80.

Kremer, C. (2011). Malaysia and Nusantara Heritage in the Adik-Abang Relationship. Stanford Journal of International Relations, 13(2), 28-29.

Kwary, D. A., \& Jalaluddin, N. H. (2014). The lexicography of Indonesian/ Malay. International Handbook of Modern Lexis and Lexicography, 1-11

Leech, G. N. (1983). Principles of Pragmatics. London: Longman.

Maher, B. (2002). Natural semantic metalanguage theory and some Italian speech act verbs. Studies in Pragmatics, 4, 33-48.

Naito, T., \& Washizu, N. (2015). Note on cultural universals and variations of gratitude from an East Asian point of view. International Journal of Behavioral Science, 10(2), 1-8.

Pishghadam, R., \& Zarei, S. (2012). Cross-cultural comparison of gratitude expressions in Persian, Chinese and American English. English Language Teaching, 5.

Saifudin, A. (2010). Analisis Pragmatik Variasi Kesantunan Tindak Tutur Terima Kasih Bahasa Jepang Dalam Film Beautiful Life Karya Kitagawa Eriko. LITE, 6(2), 172-181.

Wardhaugh, R., \& Fuller, J. M. (2015). An Introduction to Sociolinguistics: Seventh Edition. Chichester, Westsussex:Wiley Blackwell.

Wierzbicka, A. (2003). Cross-cultural pragmatics. Walter de Gruyter Inc.

Yule, George. 1996. Pragmatics . Oxford University Press. Oxford. 